\title{
Methylseleninic Acid Induces Lipid Peroxidation and Radiation Sensitivity in Head and Neck Cancer Cells
}

\author{
John T. Lafin ${ }^{1}{ }^{\oplus}$, Ehab H. Sarsour ${ }^{2}$, Amanda L. Kalen ${ }^{2}$, Brett A. Wagner ${ }^{2}($, \\ Garry R. Buettner ${ }^{2}$ and Prabhat C. Goswami ${ }^{2, *}$ \\ 1 Department of Urology, University of Texas Southwestern Medical Center, Dallas, TX 75235, USA; \\ john.lafin@utsouthwestern.edu \\ 2 The University of Iowa Free Radical and Radiation Biology Program, Department of Radiation Oncology, \\ University of Iowa, Iowa City, IA 52242, USA; ehab-sarsour@uiowa.edu (E.H.S.); \\ amanda-kalen@uiowa.edu (A.L.K.); brett-wagner@uiowa.edu (B.A.W.); garry-buettner@uiowa.edu (G.R.B.) \\ * Correspondence: prabhat-goswami@uiowa.edu; Tel.: +1-319-384-4666
}

Received: 10 November 2018; Accepted: 4 January 2019; Published: 8 January 2019

check for updates

\begin{abstract}
Combination radiation and chemotherapy are commonly used to treat locoregionally advanced head and neck squamous cell carcinoma (HNSCC). Aggressive dosing of these therapies is significantly hampered by side effects due to normal tissue toxicity. Selenium represents an adjuvant that selectively sensitizes cancer cells to these treatments modalities, potentially by inducing lipid peroxidation (LPO). This study investigated whether one such selenium compound, methylseleninic acid (MSA), induces LPO and radiation sensitivity in HNSCC cells. Results from 4,4-difluoro-4-bora-3a,4a-diaza-S-indacene (BODIPY) C11 oxidation and ferric thiocyanate assays revealed that MSA induced LPO in cells rapidly and persistently. Propidium iodide (PI) exclusion assay found that MSA was more toxic to cancer cells than other related selenium compounds; this toxicity was abrogated by treatment with $\alpha$-tocopherol, an LPO inhibitor. MSA exhibited no toxicity to normal fibroblasts at similar doses. MSA also sensitized HNSCC cells to radiation as determined by clonogenic assay. Intracellular glutathione in cancer cells was depleted following MSA treatment, and supplementation of the intracellular glutathione pool with $\mathrm{N}$-acetylcysteine sensitized cells to MSA. The addition of MSA to a cell-free solution of glutathione resulted in an increase in oxygen consumption, which was abrogated by catalase, suggesting the formation of $\mathrm{H}_{2} \mathrm{O}_{2}$. Results from this study identify MSA as an inducer of LPO, and reveal its capability to sensitize HNSCC to radiation. MSA may represent a potent adjuvant to radiation therapy in HNSCC.
\end{abstract}

Keywords: head and neck cancer; selenium; methylseleninic acid; radiation; lipid peroxidation; glutathione; tocopherol

\section{Introduction}

Head and neck squamous cell carcinoma (HNSCC) is a diverse group of cancers that originate from the mouth, nose, throat, or other nearby areas. Over 50,000 new cases of HNSCC are anticipated to arise in the US in 2018; the five-year survival rate is $~ 64 \%$ [1]. Locoregionally advanced HNSCC is often treated with combination radio- and chemotherapy. However, side effects from primary therapy can be debilitating. Radiation and chemotherapy can result in oral mucositis, which can significantly reduce tolerable doses [2]. Even with these aggressive therapy options, about $40 \%$ of HNSCC deaths will occur due to the development of therapy resistance [3]. Additional options to sensitize HNSCC cells to current therapies are sorely needed.

Selenium administration shows great promise as a sensitizer to radio- and chemotherapy. Sodium selenite, an inorganic selenium derivative, induces toxicity and radiation sensitization in various 
cancer cell types with limited effects on normal fibroblasts [4-6]. A recent metastudy reported that selenite supplementation in patients receiving radiation therapy reduced deleterious side effects with no protective effects noted in tumors, supporting the use of selenium as an adjuvant to therapy [7]. These studies and others suggest that selenium may sensitize tumors to intervention, while potentially protecting normal tissue. Unfortunately, sodium selenite exhibits toxicity at relatively low doses, with a reported maximum tolerable dose of $10.2 \mathrm{mg} \mathrm{m}^{-2}$ [8]. Organoselenium derivatives, such as selenomethionine (SLM) and methylselenocysteine (MSC), are much less toxic than their inorganic counterparts while maintaining the selective effects noted with selenite $[9,10]$. Organoselenium derivatives exert their anticancer activities through the formation of a common active metabolite, methylselenol [11,12]. SLM and MSC require the action of specific lyase enzymes, such as methionine gamma-lyase (MGL), to release methylselenol [13]. MGL expression is reported to decline in a number of cancer types, suggesting that the formation of methylselenol in tumor tissue by SLM may be slow, limiting its efficacy [14-17].

Methylseleninic acid (MSA) is an organoselenium derivative that generates methylselenol through its spontaneous reaction with free thiols, such as glutathione [18]. Because the activity of MSA is not reliant upon the expression of lyases, such as MGL, it may represent a more effective antitumor agent than other organoselenium compounds. Previous studies have reported that MSA more effectively reduces TM2H and TM12 hyperplastic mammary cell accumulation than MSC, even at 10-fold lower doses [12]. Additionally, oral administration of MSA reduced the size of PC-3 xenografts in mice by approximately $40 \%$, while administration of SLM, MSC, or sodium selenite exhibited no effects, indicating that MSA is more effective both in vitro and in vivo than other selenium compounds [19]. A combination of MSA and paclitaxel reduced the size of MDA-MB-231 xenografts in mice by about $50 \%$, compared to paclitaxel alone, suggesting that MSA may be an effective adjuvant to current therapies [20]. In these studies, no change in body weight was observed, suggesting that MSA was well tolerated.

Although methylselenol has been identified as the active antitumor metabolite of organoselenium compounds, the mechanism of action following its generation is poorly understood. The combination of MSA and glutathione has been demonstrated to increase lucigenin-based chemiluminescence, which was abrogated by the presence of superoxide dismutase, suggesting the generation of superoxide $\left(\mathrm{O}_{2}{ }^{\bullet-}\right)$ [18]. Superoxide may be protonated to form hydroperoxyl radical $\left(\mathrm{HO}_{2}{ }^{\bullet}\right)$ or dismutated to form hydrogen peroxide $\left(\mathrm{H}_{2} \mathrm{O}_{2}\right)$, both of which may contribute to the initiation of lipid peroxidation (LPO) $[21,22]$. Selenium administration has been associated with elevated markers of LPO, suggesting that these initiating effects occur in vivo [23-25]. Because end products of LPO can be highly toxic, MSA-generated methylselenol could, therefore, exhibit toxicity through the superoxide-mediated initiation of LPO. Furthermore, HNSCC patients exhibit higher levels of plasma markers of LPO than matched healthy subjects, suggesting that HNSCC may be particularly susceptible to LPO [26,27].

Results presented herein reveal that MSA exhibits toxicity and radiation sensitization of Cal27 and SCC25 HNSCC cells. Cal27 cells were found to be much more sensitive to MSA compared to SLM or MSC, while normal human fibroblasts were resistant to MSA-induced toxicity. Initiation of oxidative distress via lipid peroxidation appears to be the underlying mechanism for toxicity. Our data suggest that the toxic effects of MSA are mediated by a glutathione-dependent formation of an initiator of LPO. MSA may be a useful adjuvant to radiation therapy.

\section{Results}

\subsection{MSA is More Toxic to HNSCC Cells than Other Organoselenium Derivatives, and Causes Cell Death in a Dose- and Time-Dependent Manner}

Organoselenium derivatives SLM and MSC require enzymatic action to generate methylselenol, the common active metabolite. Therefore, methylselenol generation from SLM and MSC will be less in situations where these enzymes are poorly expressed. MSA requires no enzymatic activity to generate methylselenol [18]. To determine if MSA exhibits greater toxicity than other organoselenium 
compounds, Cal27 cells were treated with MSA, MSC, or SLM for $72 \mathrm{~h}$, and viability was assessed with propidium iodide (PI) exclusion assay. MSC and SLM exhibited no toxicity at doses up to $10 \mu \mathrm{M}$, Figure 1A. Treatment with $1 \mu \mathrm{M}$ MSA resulted in a small but significant increase in PI positive cells, while $10 \mu \mathrm{M}$ MSA resulted in about 30\% PI-positive cells. To ensure that MSA toxicity was not cell-line dependent, the effects of MSA treatment on SCC25 cells were also examined. A dose-dependent increase in PI positive SCC 25 cells was observed with MSA treatment, with approximately $30 \%$ of the cells staining positive at $10 \mu \mathrm{M}$, Figure 1B. These results indicate that Cal27 cells are more sensitive to MSA than other organoselenium derivatives and that MSA-induced toxicity is dose-dependent in both Cal27 and SCC25 cell lines.

The sensitizing effects of organoselenium compounds on cancer cells have been reported to occur as early as $24 \mathrm{~h}$ following the beginning of treatment [28]. To determine the temporal aspects of the toxicity resulting from exposure to MSA, Cal27 and SCC25 cells were treated with MSA for varying durations and the toxicity was examined by measuring changes in cell numbers as well as flow cytometry measurements of the percentage of PI-positive (non-viable) and PI-negative (viable) cell populations. SCC25 and Cal27 cells both showed a marked decline in cell number as early as $24 \mathrm{~h}$ after initiation of treatment with MSA, with a reduction in cell number of about $75 \%$ and $95 \%$ in Cal27 and SCC25, respectively, Figure 1C. Cal27 cell numbers continued to decline up to $72 \mathrm{~h}$, while SCC25 cell number appeared to begin to recover at $72 \mathrm{~h}$. The rapid onset of a reduction in cell number correlated with an increase in the percentage of PI-positive Cal 27 cells at $48 \mathrm{~h}$ of treatment, Figure 1D. SCC25 cells exhibited significant toxicity as early as $24 \mathrm{~h}$. SCC25 maximal toxicity ( $45 \%$ PI-positive cells) was reached by $48 \mathrm{~h}$ in the period examined, while Cal27 reached similar levels at $72 \mathrm{~h}$. Together, these results indicate that the MSA treatment exhibits greater toxicity to HNSCC than treatments with MSC and SLM and that this toxicity is dose- and time-dependent. Furthermore, treatment with MSA appears to be more toxic to SCC 25 compared to Cal27 cells.

A

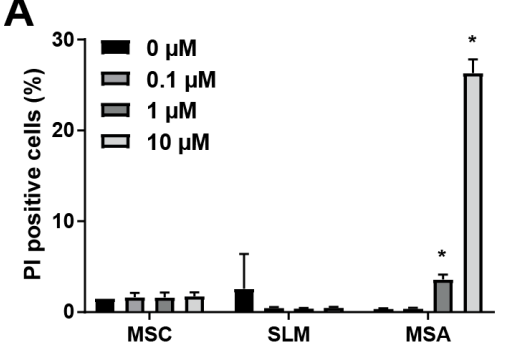

C

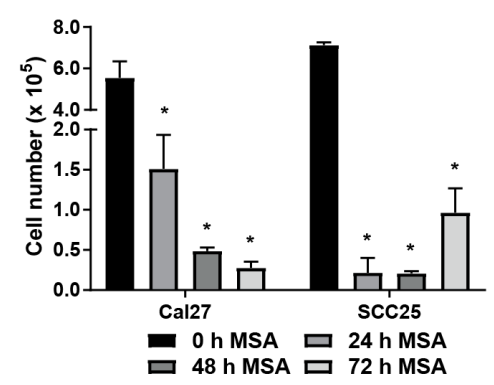

B
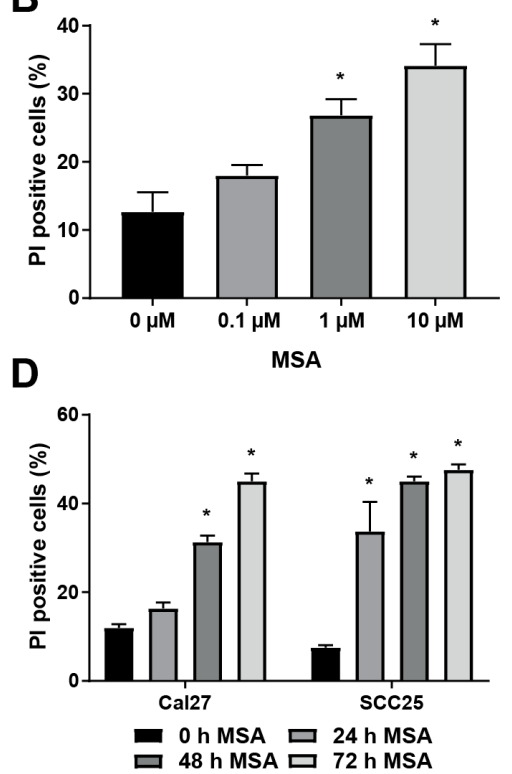

Figure 1. Methylseleninic acid (MSA) is toxic to Cal27 and SCC25 HNSCC cells in a dose- and time-dependent manner. (A) PI exclusion assay of Cal27 cells treated with the shown concentrations of Se-methylselenocysteine (MSC), seleno-L-methionine (SLM), or MSA for $72 \mathrm{~h}$. (B) Propidium iodide (PI) exclusion assay of SCC25 cells treated with 0 to $10 \mu \mathrm{M}$ MSA for $72 \mathrm{~h}$. (C) Cell counts of Cal27 and SCC25 cells following treatment with $10 \mu \mathrm{M}$ MSA for 0 to $72 \mathrm{~h}$. (D) PI exclusion assay of Cal27 and SCC25 cells after treatment with $10 \mu \mathrm{M}$ MSA for 0 to $72 \mathrm{~h}$. ${ }^{*}$, statistical significance relative to $0 \mu \mathrm{M}$ MSA controls; $p<0.05, n=3$. 


\subsection{MSA Treatment Sensitizes HNSCC Cells to Radiation}

Selenium compounds, such as sodium selenite and seleno-L-methionine, sensitize cancer cells to radiation $[4,5,10,29]$. Furthermore, this sensitization is frequently noted to be selective for cancer cells [29]. Fibroblasts are often thought to make up the majority of the non-cancer cellular fraction in the tumor stroma [30,31]. To determine if normal human fibroblasts (NHF) were resistant to MSA toxicity, a PI exclusion assay was utilized. PI-positive (non-viable) NHF population did not increase following MSA treatment, Figure 2A. MSA $(1 \mu \mathrm{M})$ treatment more than doubled non-viable Cal27 and SCC25 populations, Figure 1A,B, demonstrating the selective effects of MSA to HNSCC over NHF. To determine if MSA sensitizes HNSCC to radiation, Cal27 cells were treated with MSA for $48 \mathrm{~h}$ before 2 or 4 Gy irradiation, and toxicity was analyzed by using a clonogenic assay. Irradiated cells without MSA treatment showed a surviving fraction of 0.75 and 0.28 at 2 and $4 \mathrm{~Gy}$, respectively, Figure 2B. Treatment with $0.1 \mu \mathrm{M}$ MSA did not significantly alter surviving fraction of Cal27 cells: 0.66 and 0.22 at 2 and $4 \mathrm{~Gy}$, respectively. Interestingly, prior treatment with $1 \mu \mathrm{M}$ MSA significantly reduced the surviving fraction to 0.3 and 0.03 at 2 and 4 Gy compared to a surviving fraction of 0.75 and 0.28 without MSA treatment.

Radiation response is frequently dependent upon the support of the tumor stroma. To determine if the tumor stroma impacts the ability of MSA to sensitize Cal27 cells to radiation, a co-culture clonogenic assay was utilized. Cal27 cells were plated on lawns of quiescent normal human fibroblasts (NHF), and co-cultures were treated with $1 \mu \mathrm{M}$ MSA for $48 \mathrm{~h}$ before irradiation. Even with NHF present, MSA treatment resulted in a $40 \%$ decline of surviving fraction following 2 Gy radiation, Figure 2D. Additionally, the lawn of NHF was not disturbed by MSA, further indicating that MSA was not toxic to NHF even in combination with radiation, Figure $2 \mathrm{C}$. These results indicate that MSA treatment potently and selectively sensitizes Cal27 cells to radiation in co-cultures of NHF.

A

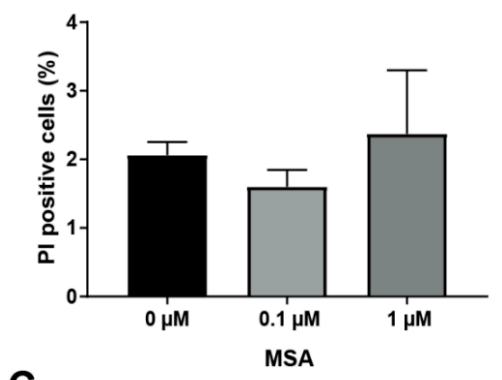

C

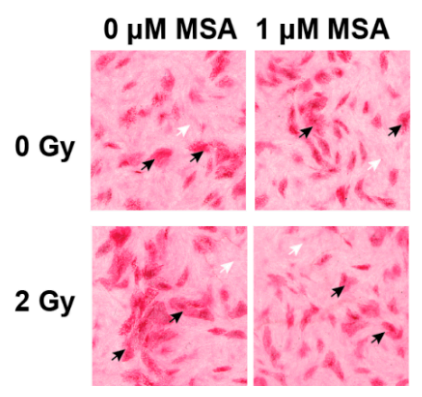

B

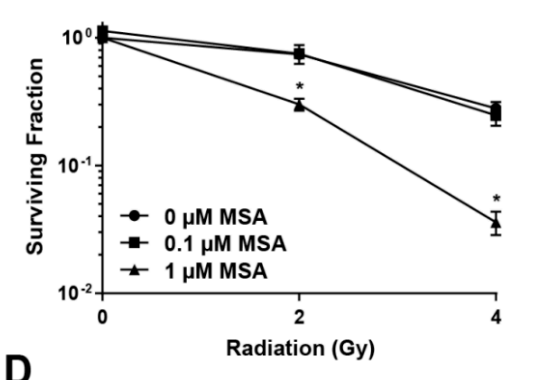

D

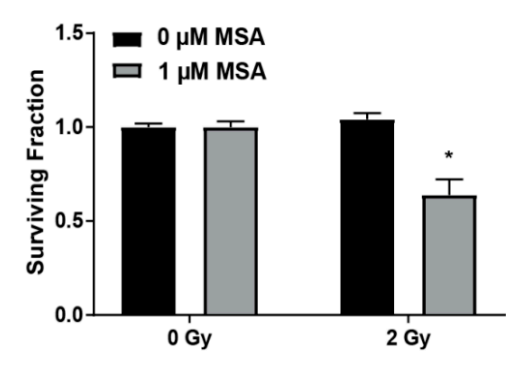

Figure 2. MSA selectively sensitizes head and neck squamous cell carcinoma (HNSCC) cells to radiation. (A) PI exclusion assay of normal human fibroblasts (NHF) treated with MSA $24 \mathrm{~h}$. (B) Clonogenic assay of Cal27 cells treated with MSA $48 \mathrm{~h}$ before irradiation with $\gamma$-rays. (C) Representative images of Cal27 cells in co-cultures with NHF that were treated with MSA $48 \mathrm{~h}$ before irradiation with $\gamma$-rays. Black arrows: Cal27 colonies; white arrows: quiescent NHF. (D) Quantitation of Cal27 clonogenic survival in co-cultures of Cal27 and NHF that were treated with MSA 48 h before irradiation with $\gamma$-rays. ${ }^{*}$, statistical significance relative to $0 \mu \mathrm{M}$ MSA controls; $p<0.05, n=3$. 


\subsection{MSA Treatment Induces Lipid Peroxidation in HNSCC Cells}

Organoselenium compounds are theorized to be metabolized through a multitude of pathways to a central active metabolite, methylselenol, which exerts toxicity. Due to the highly reactive nature of methylselenol, studies concerning its mechanism of toxicity are sorely lacking. However, markers of lipid peroxidation have been found to rise in patients treated with selenium [24], suggesting that high dose selenium may induce lipid peroxidation. To determine if MSA treatment induces lipid peroxidation in HNSCC cells, MSA-treated Cal27 cells were labeled with the dye BODIPY C-11. This dye integrates into membranes and emits maximally at $590 \mathrm{~nm}$. Upon oxidation by an initiator or propagator of lipid peroxidation, the maximal emission shifts to $510 \mathrm{~nm}$. By reading both channels simultaneously, a ratio of oxidized to reduced dye can be calculated, providing a snapshot of lipid peroxidation initiation and propagation. Lipid peroxidation was found to be up to $30 \%$ elevated in Cal27 cells treated with MSA for $72 \mathrm{~h}$, Figure 3A. An elevation was noted at a dose as low as $0.1 \mu \mathrm{M}$ MSA, suggesting a powerful potential for initiation. Examination of lipid peroxidation at very early time intervals indicated that lipid peroxidation was initiated as early as $2 \mathrm{~h}$, and maintained at a relatively stable level up to $72 \mathrm{~h}$, Figure 3B. To determine if these increases in initiation and propagation events resulted in elevated lipid hydroperoxides, the Cayman Lipid Hydroperoxide Assay kit was utilized. Cal27 cells treated with $10 \mu \mathrm{M}$ MSA for $72 \mathrm{~h}$ were found to have $1.16 \mathrm{fmol}$ lipid hydroperoxide per cell, nearly 40 times as much as untreated cells, Figure 3C. These data indicate that treatment with MSA induces lipid peroxidation potently and persistently and that this induction results in a significant accumulation of lipid hydroperoxides.

A

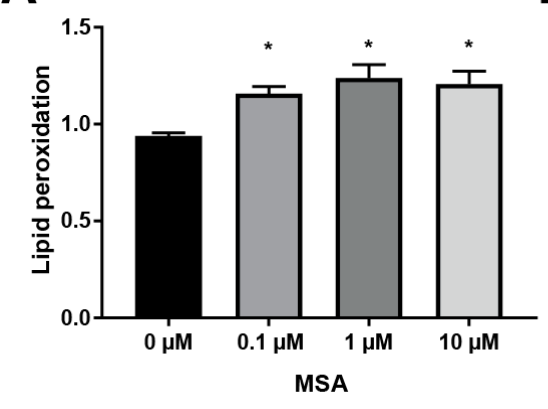

C

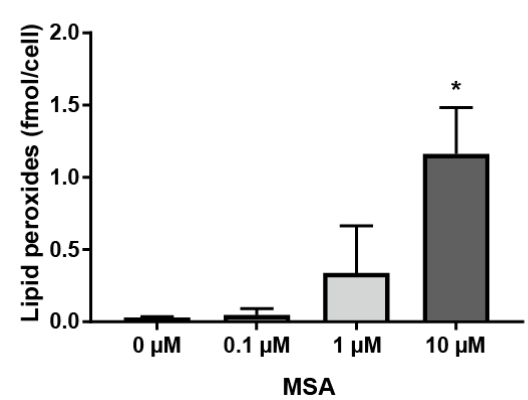

B

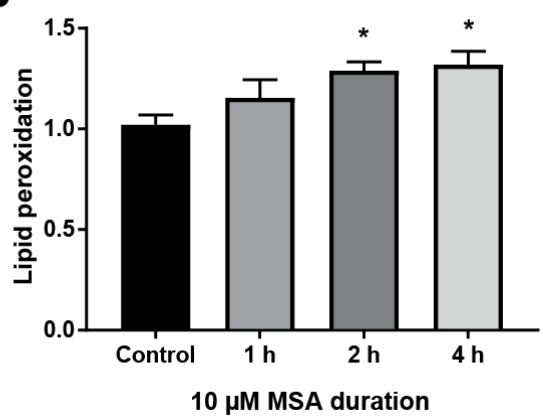

D

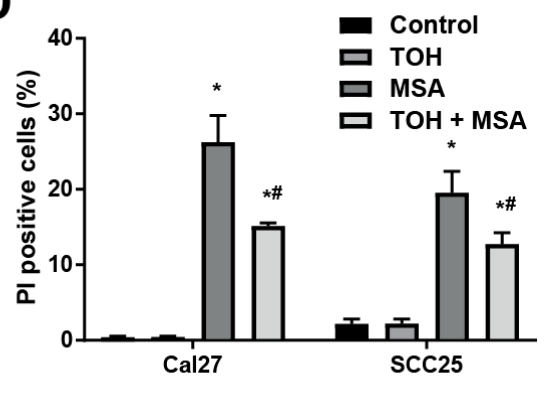

Figure 3. MSA induces lipid peroxidation in HNSCC cells. (A) Lipid peroxidation in Cal27 cells assessed by 4,4-difluoro-4-bora-3a,4a-diaza-S-indacene (BODIPY) C-11 staining following $72 \mathrm{~h}$ treatment with 0 to $10 \mu \mathrm{M}$ MSA. (B) Lipid peroxidation in Cal27 cells following treatment with $10 \mu \mathrm{M}$ MSA. (C) Lipid peroxides in Cal27 cells as assessed by the Cayman Chemical LPO Kit following treatment with 0 to $10 \mu \mathrm{M}$ MSA for $72 \mathrm{~h}$. (D) PI exclusion assay of Cal27 and SCC25 cells treated with $20 \mu \mathrm{M} \alpha$-tocopherol acetate (TOH) for $24 \mathrm{~h}, 10 \mu \mathrm{M}$ MSA for $72 \mathrm{~h}$, or pre-treatment with TOH for $24 \mathrm{~h}$ followed by treatment with MSA. *, statistical significance relative to $0 \mu \mathrm{M}$ MSA controls; \#, statistical significance relative to MSA alone; $p<0.05, n=3$. 
Lipid peroxidation is a deleterious oxidative chain reaction that can form toxic products, such as MDA or 4-HNE. Induction of uncontrolled lipid peroxidation can damage critical biomolecules resulting in cell death. To determine if MSA-induced toxicity is caused by lipid peroxidation, Cal27 and SCC 25 cells were pre-treated with a lipid peroxidation chain terminator, $\alpha$-tocopherol acetate (TOH), before MSA treatment. Treatment with TOH alone did not impact the percentage of PI-positive cell populations in either cell line, Figure 3D. However, treatment with TOH before MSA treatment reduced the percentage of the PI-positive cell population in Cal27 from $26 \%$ to $15 \%$, and in SCC25 from $20 \%$ to $12 \%$, an approximate $40 \%$ decline in the PI-positive populations. These results show that lipid peroxidation is an essential step in MSA-induced toxicity of HNSCC cells.

\subsection{N-Acetyl-L-Cysteine Exacerbates MSA Toxicity in HNSCC}

MSA spontaneously reacts with glutathione (GSH) to form its active metabolite, methylselenol, and GSH disulfide (GSSG), see below [18]. As the principal intracellular redox buffer, GSH is critical to normal cellular function. GSSG may be cytotoxic; it can be recycled to GSH by glutathione reductase, exported from the cell, or form mixed protein disulfides. To determine if MSA treatment influences GSH levels in HNSCC cells, the intracellular GSH content was measured in MSA-treated Cal27 cells using a biochemical assay [32]. Results indicate a dose-dependent decrease of total GSH in MSA-treated Cal27 cells, Figure 4A. Untreated Cal27 cells exhibited a total GSH concentration of about $17 \mathrm{nmol}$ $(\mathrm{mg} \text { protein })^{-1}$. Treatment with MSA lowered this to below $10 \mathrm{nmol}$ (mg protein $)^{-1}$, a $40 \%$ decline. Despite this marked decline, intracellular GSSG was not found to increase following MSA treatment, but rather also declined, Figure 4B. The decline in GSH levels suggests that GSH may have a significant role in the MSA-induced toxicity of HNSCC. This premise is further supported by results showing $N$-Acetyl-L-Cysteine (NAC) treatments exacerbating MSA-induced toxicity in Cal27 cells, Figure 4C. NAC is a membrane permeable precursor to GSH, stimulating its production; its effects are detectable within $4 \mathrm{~h}[33,34]$. Cal27 cells were treated with $5 \mathrm{mM} \mathrm{NAC}$ for $24 \mathrm{~h}$, washed, and treated with $10 \mu \mathrm{M}$ MSA for $72 \mathrm{~h}$. Cell number declined from $3 \times 10^{5}$ in cultures treated with MSA alone, to $0.5 \times 10^{5}$ cells, Figure 4C. A PI exclusion assay revealed that the combination of NAC and MSA resulted in a $30 \%$ non-viable cell population, while MSA alone resulted in only $25 \%$, Figure $4 \mathrm{D}$. Although NAC alone reduced cell number from $11 \times 10^{5}$ to $0.6 \times 10^{5}$, it had no effect on viability. This is consistent with prior reports from our lab that NAC treatment induces a cell cycle arrest $[33,34]$. These results indicate that GSH facilitates MSA-induced free radical chemistry (see below), leading to lipid peroxidation and HNSCC cytotoxicity. 

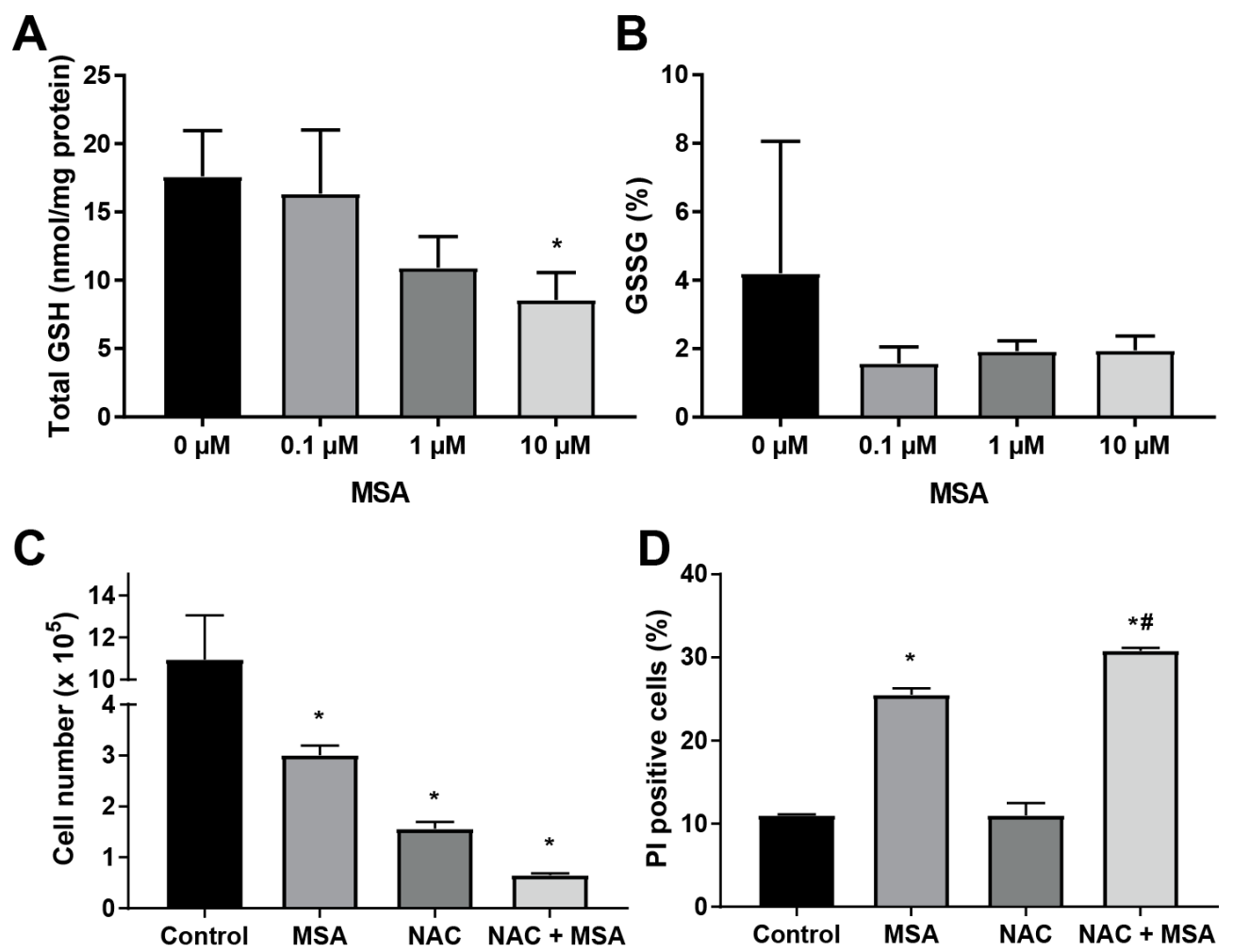

Figure 4. MSA exhibits toxicity in a glutathione (GSH)-dependent manner. (A) Total GSH in Cal27 cells treated with 0 to $10 \mu \mathrm{M}$ MSA for $72 \mathrm{~h}$. (B) Percent of GSH existing as glutathione disulfide (GSSG) in Cal27 cells treated with 0 to $10 \mu \mathrm{M}$ MSA for $72 \mathrm{~h}$. (C) Cell counts of Cal27 cells following treatment with $5 \mathrm{mM}$ N-Acetyl-L-Cysteine (NAC) for $24 \mathrm{~h}$, and/or $10 \mu \mathrm{M}$ MSA for $72 \mathrm{~h}$. The NAC + MSA group received 5 mM NAC for $24 \mathrm{~h}$ before treatment with MSA. (D) PI exclusion assay of Cal27 cells treated with $5 \mathrm{mM} \mathrm{NAC}$ for $24 \mathrm{~h}$, and/or $10 \mu \mathrm{M}$ MSA for $72 \mathrm{~h}$. The NAC + MSA group received $5 \mathrm{mM}$ NAC for $24 \mathrm{~h}$ before treatment with MSA. *, statistical significance relative to $0 \mu \mathrm{M}$ MSA controls; \#, statistical significance relative to NAC alone; $p<0.05, n=3$.

\subsection{MSA Treatment Enhances GSH-Dependent $\mathrm{O}_{2}$ Consumption}

MSA can be reduced by free thiols, such as GSH, to form its active metabolite, methylselenol, Figure 5C. Because the $\mathrm{p} K_{\mathrm{a}}$ of the selenohydryl group is 5.2, it primarily exists in biological systems as its conjugate base, the highly reactive methylselenolate anion $\left(\mathrm{MeSe}^{-}\right)$[35]. This reactive species may initiate a cyclic reaction with molecular oxygen and GSH to cycle between a methylselenyl radical intermediate and methylselenolate anion, forming $\mathrm{O}_{2}{ }^{\bullet-}$ (which is rapidly dismuted to $\mathrm{H}_{2} \mathrm{O}_{2}$ ) and GSH to GSSG as products. This cyclic reaction is anticipated to account for the toxicity of organoselenium compounds $[18,36]$. In support of this chemistry, a previous study demonstrated the involvement of oxygen to the cyclic reaction between a related compound, selenocystamine, and GSH [36]. To determine if MSA may also undergo a similar reaction, $\mathrm{O}_{2}$ consumption was monitored in a cell-free system containing MSA and GSH, Figure 5A. This system was held at pH 9.2, as this is the reported optimum $\mathrm{pH}$ for selenium-catalyzed $\mathrm{O}_{2}{ }^{\bullet-}$ generation [18]. $\mathrm{O}_{2}$ was observed to disappear from the buffer at a rate of approximately $3 \mathrm{nM} \mathrm{s}^{-1}$. Addition of MSA to buffer did not change the rate of consumption of $\mathrm{O}_{2}$ (data not shown). Addition of GSH in the absence of MSA resulted in the disappearance of $\mathrm{O}_{2}$ at a rate of approximately $15 \mathrm{nM} \mathrm{s}^{-1}$, Figure 5B. Interestingly, the addition of MSA $(250 \mu \mathrm{M})$ following GSH doubled the rate of $\mathrm{O}_{2}$ consumption to approximately $32 \mathrm{nM} \mathrm{s}^{-1}$. Furthermore, the addition of $500 \mathrm{IU}$ catalase caused the rate of $\mathrm{O}_{2}$ consumption to return to $13 \mathrm{nM}$ $\mathrm{s}^{-1}$, approximately the same as GSH alone. These results indicate an $\mathrm{O}_{2}$-dependent reaction occurring between MSA and GSH that may result in the formation, but not accumulation, of $\mathrm{H}_{2} \mathrm{O}_{2} \cdot \mathrm{H}_{2} \mathrm{O}_{2}$ may also contribute to another $\mathrm{O}_{2}$-dependent reaction between GSH and MSA. The resulting flux 
of $\mathrm{H}_{2} \mathrm{O}_{2}$ may facilitate lipid peroxidation through the iron-dependent generation of $\mathrm{HO}^{\bullet}$, resulting in MSA-induced toxicity of HNSCC. Previous reports indicate elevated markers of LPO in HNSCC patients [26,27], suggesting that MSA-induced selective cytotoxicity may be due to higher baseline levels of LPO in HNSCC compared to normal cells.

A

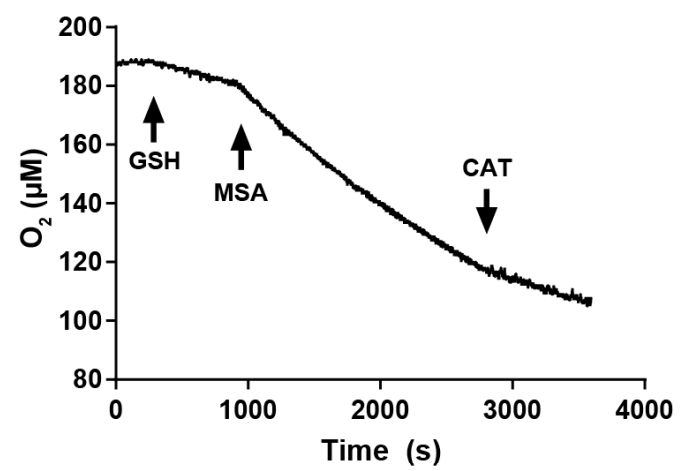

C

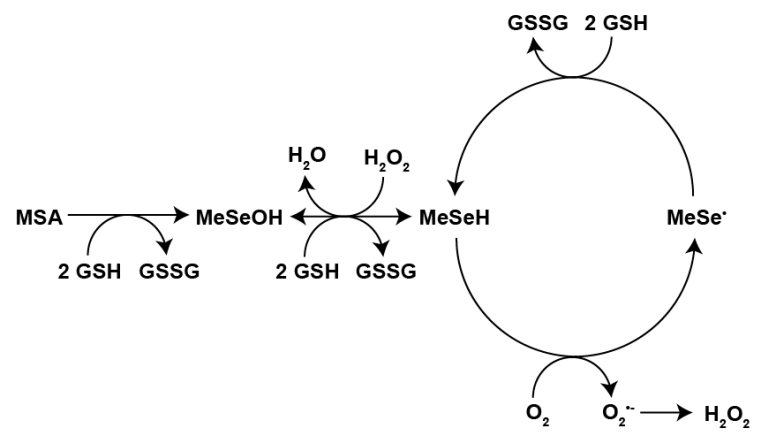

B

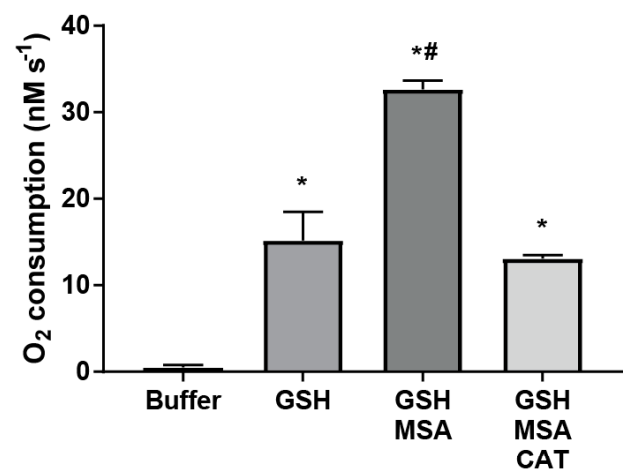

D

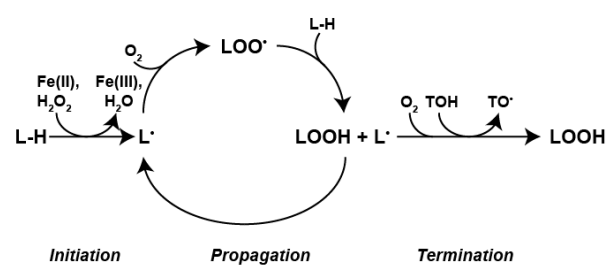

Figure 5. MSA enhances the consumption of $\mathrm{O}_{2}$ by glutathione. (A) Representative trace of $\mathrm{O}_{2}$ concentration in $3.00 \mathrm{~mL} \mathrm{pH} 9.250 \mathrm{mM}$ borate buffer at $37{ }^{\circ} \mathrm{C}$. GSH and MSA added to a final concentration of $2 \mathrm{mM}$ and $250 \mu \mathrm{M}$, respectively, at indicated time points. (B) Rate of $\mathrm{O}_{2}$ consumption in $3.00 \mathrm{~mL} \mathrm{pH} \mathrm{9.2,50} \mathrm{mM} \mathrm{borate} \mathrm{buffer} \mathrm{at} 37^{\circ} \mathrm{C}$. (C) Schematic of metabolism of MSA. MSA is reduced by GSH to methylselenol (MeSeH) through a methylselenenic acid (MeSeOH) intermediate. $\mathrm{MeSeH}$ may cycle with $\mathrm{O}_{2}$ and GSH through a methylselenyl radical intermediate $(\mathrm{MeSe})^{\bullet}$ to generate $\mathrm{H}_{2} \mathrm{O}_{2}$, potentially through an $\mathrm{O}_{2}{ }^{\bullet-}$ intermediate. MeSeH may also exhibit peroxidase activity, consuming $\mathrm{H}_{2} \mathrm{O}_{2}$. (D) Schematic of the process of lipid peroxidation. The process is initiated by abstraction of a hydrogen atom from a lipid, forming a carbon-centered lipid radical $\left(\mathrm{L}^{\bullet}\right)$. The reaction is propagated by the addition of $\mathrm{O}_{2}$, followed by abstraction of another hydrogen atom from a neighboring lipid, forming $\mathrm{LOOH}$ and a new $\mathrm{L}^{\bullet}$. The chain can be terminated by a donor antioxidant, such as tocopherol (TOH). The resulting tocopheroxyl radical $\left(\mathrm{TO}^{\bullet}\right)$ radical does not efficiently further oxidize lipids. *, statistical significance relative to buffer alone; \#, statistical significance to GSH alone; $p<0.05, n=3$.

\section{Discussion}

Results presented here show that MSA treatment results in toxicity and enhanced radiation sensitivity in HNSCC cells and that this toxicity may be facilitated by glutathione and oxygen-mediated reactions resulting in toxicity. BODIPY C-11 oxidation data indicate that lipid peroxidation is associated with this oxidative process, can be detected within $2 \mathrm{~h}$ of the initiation of MSA treatment, and persists for at least $72 \mathrm{~h}$. Lipid hydroperoxides were detected in a dose-dependent manner following treatment with MSA, consistent with a role for lipid peroxidation and corroborating BODIPY C-11 oxidation experiments. In a cell-free system, MSA doubled the rate of GSH-dependent $\mathrm{O}_{2}$ consumption. Consistent with results from the cell-free experiments, intracellular GSH levels decline in Cal27 cells following exposure to MSA. Supplementation of the intracellular GSH pool by pre-treatment with 
NAC further sensitized, rather than protected, the cells from MSA-induced toxicity. These results suggest that MSA reacts with intracellular GSH, yielding reactive oxygen species capable of inducing lipid peroxidation and cell death.

MSA exhibited significant toxicity to Cal27 and SCC25 HNSCC cells, Figure 1. Similar organoselenium compounds SLM and MSC did not show any toxicity at doses up to $10 \mu \mathrm{M}$, while $10 \mu \mathrm{M}$ MSA resulted in a nearly 30\% PI-positive (non-viable) population of cells, Figure 1A. The active metabolite of all three of the examined compounds is methylselenol [11,12]. SLM and MSC release methylselenol following processing by lyase enzymes, such as MGL [13]. Several reports have identified MGL as a tumor suppressor gene, suggesting that its expression is reduced in tumors [14-17]. Overexpression of MGL in ovarian cancer cells resulted in up to 1000-fold sensitization to SLM [37]. Furthermore, hepatoma xenografts treated with the combination of adenovirus-delivered MGL and SLM $\left(1 \mu \mathrm{mol} \mathrm{d}^{-1}, \mathrm{IP}\right)$ exhibited a drastic decline in tumor size compared to SLM alone, indicating the necessity of MGL for SLM to generate methylselenol [37]. MSA generates methylselenol by a direct and spontaneous reaction with GSH, obviating the need for MGL, Figure 5C [13,18]. Previous studies have identified MSA as more effective than MSC at inducing apoptosis and inhibiting cell growth in murine mammary cell cultures [12]. MSA also more effectively reduced prostate cancer xenograft size than SLM or MSC with no change in body weight [19]. Our results indicate that HNSCC is also more sensitive to MSA than SLM or MSC. MSA was also found to render Cal27 HNSCC cells sensitive to radiation, Figure 2B. Although other selenium compounds have been reported to induce sensitivity of cancer cells to radiation, the ability of MSA to do so has not yet been reported $[4,10]$. The increased toxicity of MSA compared to other selenium compounds suggests that it may also more effectively sensitize cancer cells to radiation. Additionally, the cytotoxic and sensitizing effects appear to be selective to cancer cells, as NHF were relatively resistant to MSA-induced toxicity, Figure 2A, and quiescent lawns of NHF were undisturbed by a combination of MSA and radiation, Figure 2C.

MSA treatment increased BODIPY C11 oxidation in Cal27 cells, Figure 3A,B. BODIPY C11 may be oxidized by LPO initiators, such as hydroperoxyl radical, and propagators, such as lipid peroxyl radical [38]. The dye is insensitive to $\mathrm{LOOH}$ and aldehydic end products of LPO, such as malondialdehyde (MDA) or 4-hydroxynonenal (4-HNE). A dose-dependent increase of BODIPY C11 oxidation was not observed at $72 \mathrm{~h}$ of MSA treatment. However, MSA treatment did result in a dose-dependent increase in the accumulation of $\mathrm{LOOH}$, as determined by the Cayman LPO Kit, Figure 3C. Additionally, BODIPY C11 dye oxidation was found to stabilize as early as $2 \mathrm{~h}$ of MSA treatment, Figure 3B. These results suggest that MSA induces LPO rapidly and persistently and that this results in an accumulation of toxic lipid hydroperoxides. Furthermore, LPO appears essential to the toxicity of MSA, as pre-treatment with $\alpha$-tocopherol acetate, an inhibitor of LPO, protected the cells from MSA-induced toxicity, Figure 3D. Previous studies have mainly focused on selenium administration as an inhibitor of LPO, presumably due to the induction of the glutathione peroxidase system [39]. However, evidence exists to suggest that selenium may initiate rather than inhibit LPO. Pre-treatment with sodium selenite (single dose $2 \mathrm{mg} \mathrm{kg}^{-1}, \mathrm{IP}$ ) in a murine model of heavy metal poisoning found a 4 -fold increase of liver MDA content over metal alone [23]. Administration of ebselen, a synthetic organoselenium compound, increased liver MDA content in rats by approximately $20 \%$ [25]. Serum MDA levels were elevated in ovarian cancer patients following the administration of $50 \mu \mathrm{g}$ of selenium as selenized yeast (4.8 $\mu \mathrm{M}$ compared to $3.9 \mu \mathrm{M})$ [24]. These reports and others suggest that in some circumstances, selenium administration may induce LPO, although the mechanisms are yet unclear. Because MSA more effectively generates methylselenol, the active metabolite, than similar selenium compounds, it may also more potently induce LPO.

MSA treatment of Cal27 cells resulted in a depletion of total intracellular GSH content, Figure 4A,B. MSA has been reported to deplete GSH in A549 lung cancer and HepG2 hepatoma cells [40,41]. In HepG2 cells, a biphasic response was noted: A $10 \mu \mathrm{M}$ treatment of MSA for $24 \mathrm{~h}$ caused intracellular GSH to increase by about $75 \%$, while $25 \mu \mathrm{M}$ MSA resulted in an approximate $20 \%$ decline in GSH, with no change in GSSG. This biphasic response was not noted in Cal27 cells; total GSH content was 
unchanged or declined at all doses tested, Figure 3A. Furthermore, treatment with MSA $(10 \mu \mathrm{M})$ for $24 \mathrm{~h}$ decreased cell numbers of Cal27 and SCC25; a significant increase in the non-viable population, Figure 1C,D. Apoptosis of HepG2 cells as detected by LDH was not noted at $10 \mu \mathrm{M}$ MSA for $24 \mathrm{~h}$, suggesting that HepG2 cells are more resistant to MSA than HNSCC [41]. This concentration coincides with elevated GSH in HepG2, which suggests that the biphasic response may play a role in resistance of MSA. Interestingly, despite a decline in intracellular GSH levels following MSA treatment, no change was noted in GSSG, Figure 4B. This may be due to increased GSSG efflux through membrane transporters, such as MRP1 [42]. GSH may also be consumed without GSSG formation through conjugation, suggesting that MSA treatment may induce increased GSH conjugation forming mixed disulfides. Supplementation of the intracellular thiol pool by pre-treatment with NAC sensitized Cal27 cells to MSA, Figure 4C,D. Similar results were reported with MSA treatment of HepG2 cells [41]. These results suggest that a reaction between MSA and a thiol, such as GSH, is essential for MSA-induced cytotoxicity.

Oxygen consumption by GSH was doubled in the presence of MSA in a cell-free system, Figure 5A,B. Furthermore, the addition of catalase to this system returned the rate of $\mathrm{O}_{2}$ consumption to those similar to GSH alone. These results suggest the formation, but not accumulation, of $\mathrm{H}_{2} \mathrm{O}_{2}$. $\mathrm{Had} \mathrm{H}_{2} \mathrm{O}_{2}$ accumulated, the addition of catalase would have returned $\mathrm{O}_{2}$ to the system, i.e., an increase in the concentration of $\mathrm{O}_{2}$ would have been observed. Selenol species may exhibit peroxidase activity, as evidenced by the active site selenol of selenium-containing glutathione peroxidases [36]. Methylselenol may, therefore, exhibit peroxidase activity, yielding a methylselenenic acid, which may again react with GSH to regenerate methylselenol, Figure 5C. Previous reports indicate the potential for the formation of $\mathrm{O}_{2}{ }^{--}$in systems containing selenium and GSH. The addition of MSA to a solution of GSH is reported to increase lucigenin-based chemiluminescence $[13,18]$. This effect was abrogated by the presence of superoxide dismutase, suggesting the formation of $\mathrm{O}_{2}{ }^{\bullet-}$. Additionally, an examination of the reaction kinetics of GSH and selenocystamine, an organoselenium compound similar to MSA, suggests a cyclic reaction yielding superoxide [36]. Following $\mathrm{O}_{2}{ }^{--}$generation, methylselenol may be regenerated by an additional reduction by GSH, yielding a cyclic reaction capable of generating large amounts of $\mathrm{O}_{2}{ }^{\bullet-}[18,36]$. These reactions are summarized in Figure 5C. Following its formation, $\mathrm{O}_{2}{ }^{--}$can dismute to $\mathrm{H}_{2} \mathrm{O}_{2}$, either spontaneously or through the action of superoxide dismutase [43]. $\mathrm{H}_{2} \mathrm{O}_{2}$ may contribute to LPO initiation through the generation of hydroxyl radical by iron-mediated Fenton chemistry $[44,45]$. Superoxide can also be protonated to form hydroperoxyl radical, which is a powerful LPO initiator [21,22]. The contribution of $\mathrm{O}_{2}{ }^{\bullet-}$ to selenium-based cytotoxicity has been further demonstrated by the protective effects of a superoxide dismutase mimetic [46]. Methylselenol may, therefore, initiate lipid peroxidation chain reactions through superoxide-mediated products.

Overall, results from this study indicate that MSA sensitizes HNSCC cell to radiation and exhibits toxicity through a GSH-dependent induction of LPO. LPO occurs more readily in cells with higher polyunsaturated fatty acid content [47]. Many types of cancer exhibit greater lipid content than their respective normal counterparts, including colon, prostate, pancreatic, and clear cell renal carcinoma [4852]. MSA may, therefore, exhibit selective cytotoxicity in cancer cells on the basis of altered lipid content. A pre-clinical study examining the efficacy of MSA $\left(4 \mathrm{mg} \mathrm{kg}^{-1} \mathrm{~d}^{-1}, \mathrm{PO}\right)$ in treating prostate cancer xenografts found a nearly $40 \%$ reduction in tumor size following MSA treatment, with no change in body weight [19]. Similarly, MSA ( $4.5 \mathrm{mg} \mathrm{kg}^{-1} \mathrm{~d}^{-1}$, PO) combined with paclitaxel $\left(10 \mathrm{mg} \mathrm{kg}^{-1}\right.$ week $^{-1}$, IP) reduced breast cancer xenograft tumor size with no change in body weight [20]. These studies suggest that MSA is selectively toxic to cancer cells. The work presented herein suggests that this selectivity may be in part due to a differential sensitivity to LPO in cancer compared to normal cells. 


\section{Materials and Methods}

\subsection{Cell Culture and Reagents}

Head and neck squamous carcinoma cell lines Cal27 (tongue origin, CRL-2095) and SCC25 (tongue origin, CRL-1628) were purchased from ATCC (Manassas, VA, USA). Both lines have mutated p53, are epidermal growth factor receptor (EGFR) positive, and human papillomavirus (HPV) negative. Normal human fibroblasts (NHF) were obtained from the Coriell cell repository (AG01522D). Cells were cultured in Dulbecco's Modified Eagle's Medium (DMEM) (Thermo Fisher Scientific, Waltham, MA, USA), supplemented with antibiotics and 10\% bovine calf serum (HNSCC cells, Thermo Fisher Scientific, Waltham, MA, USA) or 10\% fetal bovine serum (NHF, Sigma-Aldrich, St. Louis, MO, USA). All cells were grown in humidified incubators set to $37^{\circ} \mathrm{C}, 5 \% \mathrm{CO}_{2}$, and atmospheric oxygen.

Seleno-L-methionine (SLM, S3132), N-acetylcysteine (NAC, A9165), glutathione (GSH, G4251), glutathione disulfide (GSSG, G4376), glutathione reductase (GR, G3664), 2-vinylpyridine (2-VP, 132292), 5,5-dithio-bis-(2-nitrobenzoic acid) (DTNB, D8130), and 5-sulfosalicylic acid (SSA, S2130) were purchased from Sigma-Aldrich. Reduced nicotinamide adenine dinucleotide phosphate (NADPH) (481973) was purchased from EMD Millipore (Burlington, MA, USA). Methyl-Se-selenocysteine (MSC) and methylseleninic acid (MSA) were generous gifts of the laboratory of Youcef Rustum (Roswell Park Cancer Institute, Buffalo, NY, USA). BODIPY 581/591 C-11 (D3861) and CellTracker Green CMFDA (C7025) were purchased from Thermo Fisher Scientific (Waltham, MA, USA). Lipid Hydroperoxide (LPO) Assay Kit (705002) was purchased from Cayman Chemical Company (Ann Arbor, MI, USA).

\subsection{Irradiation}

Exponentially growing cells were irradiated at the Free Radical and Radiation Research Core Facility at The University of Iowa. All irradiated cells received a single dose of $\gamma$-rays from a cesium-137 irradiator (JL Shephard, San Fernando, CA, USA) at a dose rate of $0.65 \mathrm{~Gy} \mathrm{~min}^{-1}$. Cell survival was measured using a clonogenic assay following a previously published method [53].

\subsection{Propidium Iodide Exclusion Assay}

Following treatment, cultures were trypsinized, washed, and resuspended in cold phosphate buffered saline (PBS). The suspended cultures were filtered and labeled with $1 \mu \mathrm{g} \mathrm{mL} \mathrm{m}^{-1}$ propidium iodide for $5 \mathrm{~min}$ on ice. Flow cytometry was completed on a Becton-Dickinson FACScan at the University of Iowa Flow Cytometry Core. Data from 10,000 events were collected in list mode. The population of PI-positive (non-viable) and negative (viable) cells were calculated with FlowJo software (FlowJo, LLC, Ashland, Oregon, USA).

\subsection{BODIPY C-11 Assay}

Following MSA treatment, adherent cells were washed and labeled with $5 \mu \mathrm{M}$ BODIPY C-11 in DMEM lacking serum and antibiotics for $15 \mathrm{~min}$ at $37^{\circ} \mathrm{C}$. Following labeling, cultures were collected by trypsinization, washed, resuspended in cold PBS and filtered. Samples were read on a Becton-Dickinson LSR II flow cytometer using channels for Texas Red (reduced dye) and fluorescein isothiocyanate (FITC, oxidized dye) simultaneously at The University of Iowa Flow Cytometry Core. Populations were gated and analyzed with FlowJo software (version 7.6.5), and ratios of oxidized:reduced dye were calculated.

\subsection{Total Lipid Hydroperoxide Determination}

A Cayman Lipid Hydroperoxide Assay Kit was used to determine total lipid hydroperoxides in cell samples. Cal27 cells were treated with MSA for $72 \mathrm{~h}$. Following treatment, cells were collected by trypsinization and counted. Total lipid extracts were obtained and analyzed as recommended by the manufacturer in glass cuvettes on a Beckman DU650 spectrophotometer. Lipid hydroperoxides per 
cell was quantified by construction of an appropriate standard curve and normalized to cell number, as determined by a Z1 Coulter Counter (Beckman-Coulter, Brea, CA, USA).

\subsection{Glutathione Determination}

Following treatment, cells were collected by trypsinization, washed, and pellets were lysed in ice cold $5 \%$ sulfosalicylic acid. Extracts were stored at $-80{ }^{\circ} \mathrm{C}$ until analysis. Following centrifugation, the supernatant was removed and used for the glutathione assay; protein precipitate was dissolved in $1 \%$ SDS, $0.1 \mathrm{M} \mathrm{NaOH}$ for protein determination. Total glutathione was determined as described previously on a Beckman DU-650 spectrophotometer [54]. Glutathione disulfide (GSSG) was determined using the method of Griffith and Anderson [32]. Rates of reaction were compared to glutathione or glutathione disulfide standard curves and normalized to protein content as determined by bicinchoninic acid (BCA) (Thermo Fisher Scientific, Manassas, VA, USA).

\subsection{Oxygen Consumption}

Involvement of oxygen in the reactions of glutathione and MSA was investigated by recording oxygen consumption during reaction progress in a cell-free system with an ESA BioStat Multi Electrode System and YSI Oxygen Probe (Yellow Springs Instrument Co., Yellow Springs, OH, USA) at the Free Radical and Radiation Research Core Facility at The University of Iowa. Measurements were conducted in $3.00 \mathrm{~mL}$ of $50 \mathrm{mM} \mathrm{pH} 9.2$ borate buffer at $37^{\circ} \mathrm{C}$. Initial oxygen concentration was assumed to be $188 \mu \mathrm{M}$, as reported previously [55]. The reactants glutathione, MSA, and catalase were introduced sequentially to final concentrations of $2 \mathrm{mM}, 250 \mu \mathrm{M}$, and $167 \mathrm{IU} \mathrm{mL}^{-1}$, respectively.

\subsection{Statistical Analysis}

Statistical analysis was completed using Prism (GraphPad Software, San Diego, CA, USA). Two-way ANOVA with post-hoc analysis was completed to determine statistical significance. Homogeneity of variance was assumed at a 95\% confidence interval. Results from at least three biological replicates with $p<0.05$ were considered significant.

Author Contributions: Conceptualization, P.C.G., G.R.B., J.T.L., E.H.S., B.A.W.; methodology, J.T.L., E.H.S., B.A.W., G.R.B.; validation, J.T.L. and A.L.K.; formal analysis, J.T.L., B.A.W., E.H.S.; investigation, J.T.L., A.L.K.; resources, P.C.G., G.R.B.; writing—original draft preparation, J.T.L.; writing—review and editing, P.C.G., G.R.B.; visualization, J.T.L.; supervision, P.C.G., G.R.B.; project administration, P.C.G.; funding acquisition, P.C.G.

Funding: This research was supported by funding from NIH 2R01 CA111365 (P.C.G.), R01 CA169046 (G.R.B.) and T32 CA078586.

Acknowledgments: Youcef Rustum provided methylseleninic acid (MSA) and methylselenocysteine (MSC) as a generous gift for the completion of these studies. We thank Justin Fishbaugh and The University of Iowa Flow Cytometry Core for their aid in completing the flow cytometry measurements. We also thank Michael McCormick and The University of Iowa Free Radical and Radiation Research Core Facility for their expertise in biochemical measurements and irradiation services.

Conflicts of Interest: The authors declare no conflict of interest.

\section{References}

1. Howlader, N.A.; Krapcho, M.; Miller, D.; Bishop, K.; Altekruse, S.F.; Kosary, C.L.; Yu, M.; Ruhl, J.; Tatalovich, Z.; Mariotto, A.; et al. SEER Cancer Statistics Review, 1975-2013; National Cancer Institute: Bethesda, MD, USA, 2016.

2. Orlandi, E.; Iacovelli, N.A.; Rancati, T.; Cicchetti, A.; Bossi, P.; Pignoli, E.; Bergamini, C.; Licitra, L.; Fallai, C.; Valdagni, R.; et al. Multivariable model for predicting acute oral mucositis during combined IMRT and chemotherapy for locally advanced nasopharyngeal cancer patients. Oral Oncol. 2018, 86, 266-272. [CrossRef]

3. Pulte, D.; Brenner, H. Changes in survival in head and neck cancers in the late 20th and early 21st century: A period analysis. Oncologist 2010, 15, 994-1001. [CrossRef]

4. Schueller, P.; Puettmann, S.; Micke, O.; Senner, V.; Schaefer, U.; Willich, N. Selenium influences the radiation sensitivity of C6 rat glioma cells. Anticancer Res. 2004, 24, 2913-2917. 
5. Husbeck, B.; Peehl, D.M.; Knox, S.J. Redox modulation of human prostate carcinoma cells by selenite increases radiation-induced cell killing. Free Radic. Biol. Med. 2005, 38, 50-57. [CrossRef]

6. Eckers, J.C.; Kalen, A.L.; Xiao, W.; Sarsour, E.H.; Goswami, P.C. Selenoprotein P inhibits radiation-induced late reactive oxygen species accumulation and normal cell injury. Int. J. Radiat. Oncol. Biol. Phys. 2013, 87, 619-625. [CrossRef]

7. Puspitasari, I.M.; Abdulah, R.; Yamazaki, C.; Kameo, S.; Nakano, T.; Koyama, H. Updates on clinical studies of selenium supplementation in radiotherapy. Radiat. Oncol. 2014, 9, 125. [CrossRef]

8. Brodin, O.; Eksborg, S.; Wallenberg, M.; Asker-Hagelberg, C.; Larsen, E.H.; Mohlkert, D.; Lenneby-Helleday, C.; Jacobsson, H.; Linder, S.; Misra, S.; et al. Pharmacokinetics and Toxicity of Sodium Selenite in the Treatment of Patients with Carcinoma in a Phase I Clinical Trial: The SECAR Study. Nutrients 2015, 7, 4978-4994. [CrossRef]

9. Ammar, E.M.; Couri, D. Acute toxicity of sodium selenite and selenomethionine in mice after ICV or IV administration. Neurotoxicology 1981, 2, 383-386.

10. Shin, S.H.; Yoon, M.J.; Kim, M.; Kim, J.I.; Lee, S.J.; Lee, Y.S.; Bae, S. Enhanced lung cancer cell killing by the combination of selenium and ionizing radiation. Oncol. Rep. 2007, 17, 209-216. [CrossRef]

11. Ip, C. Lessons from basic research in selenium and cancer prevention. J. Nutr. 1998, 128, 1845-1854. [CrossRef]

12. Ip, C.; Thompson, H.J.; Zhu, Z.; Ganther, H.E. In vitro and in vivo studies of methylseleninic acid: Evidence that a monomethylated selenium metabolite is critical for cancer chemoprevention. Cancer Res. 2000, 60, 2882-2886.

13. Spallholz, J.E.; Palace, V.P.; Reid, T.W. Methioninase and selenomethionine but not Se-methylselenocysteine generate methylselenol and superoxide in an in vitro chemiluminescent assay: Implications for the nutritional carcinostatic activity of selenoamino acids. Biochem. Pharmacol. 2004, 67, 547-554. [CrossRef]

14. Tan, Y.; Sun, X.; Xu, M.; Tan, X.; Sasson, A.; Rashidi, B.; Han, Q.; Tan, X.; Wang, X.; An, Z.; et al. Efficacy of recombinant methioninase in combination with cisplatin on human colon tumors in nude mice. Clin. Cancer Res. Off. J. Am. Assoc. Cancer Res. 1999, 5, 2157-2163.

15. Yoshioka, T.; Wada, T.; Uchida, N.; Maki, H.; Yoshida, H.; Ide, N.; Kasai, H.; Hojo, K.; Shono, K.; Maekawa, R.; et al. Anticancer efficacy in vivo and in vitro, synergy with 5-fluorouracil, and safety of recombinant methioninase. Cancer Res. 1998, 58, 2583-2587.

16. Kokkinakis, D.M.; Hoffman, R.M.; Frenkel, E.P.; Wick, J.B.; Han, Q.; Xu, M.; Tan, Y.; Schold, S.C. Synergy between methionine stress and chemotherapy in the treatment of brain tumor xenografts in athymic mice. Cancer Res. 2001, 61, 4017-4023.

17. Hu, J.; Cheung, N.K. Methionine depletion with recombinant methioninase: In vitro and in vivo efficacy against neuroblastoma and its synergism with chemotherapeutic drugs. Int. J. Cancer 2009, 124, 1700-1706. [CrossRef]

18. Spallholz, J.E.; Shriver, B.J.; Reid, T.W. Dimethyldiselenide and methylseleninic acid generate superoxide in an in vitro chemiluminescence assay in the presence of glutathione: Implications for the anticarcinogenic activity of L-selenomethionine and L-Se-methylselenocysteine. Nutr. Cancer 2001, 40, 34-41. [CrossRef]

19. Li, G.-X.; Lee, H.-J.; Wang, Z.; Hu, H.; Liao, J.D.; Watts, J.C.; Combs, G.F.; Lü, J. Superior in vivo inhibitory efficacy of methylseleninic acid against human prostate cancer over selenomethionine or selenite. Carcinogenesis 2008, 29, 1005-1012. [CrossRef]

20. Qi, Y.; Fu, X.; Xiong, Z.; Zhang, H.; Hill, S.M.; Rowan, B.G.; Dong, Y. Methylseleninic acid enhances paclitaxel efficacy for the treatment of triple-negative breast cancer. PLOS ONE 2012, 7, e31539. [CrossRef]

21. Aikens, J.; Dix, T.A. Perhydroxyl radical (HOO.) initiated lipid peroxidation. The role of fatty acid hydroperoxides. J. Biol. Chem. 1991, 266, 15091-15098.

22. Bielski, B.H.; Arudi, R.L.; Sutherland, M.W. A study of the reactivity of $\mathrm{HO} 2 / \mathrm{O} 2-$ with unsaturated fatty acids. J. Biol. Chem. 1983, 258, 4759-4761.

23. Rungby, J. Silver-induced lipid peroxidation in mice: Interactions with selenium and nickel. Toxicology 1987, 45, 135-142. [CrossRef]

24. Sieja, K.; Talerczyk, M. Selenium as an element in the treatment of ovarian cancer in women receiving chemotherapy. Gynecol. Oncol. 2004, 93, 320-327. [CrossRef]

25. Farina, M.; Soares, F.A.; Zeni, G.; Souza, D.O.; Rocha, J.B. Additive pro-oxidative effects of methylmercury and ebselen in liver from suckling rat pups. Toxicol. Lett. 2004, 146, 227-235. [CrossRef] 
26. Rasheed, M.H.; Beevi, S.S.; Geetha, A. Enhanced lipid peroxidation and nitric oxide products with deranged antioxidant status in patients with head and neck squamous cell carcinoma. Oral Oncol. 2007, 43, 333-338. [CrossRef]

27. Gupta, A.; Bhatt, M.L.; Misra, M.K. Lipid peroxidation and antioxidant status in head and neck squamous cell carcinoma patients. Oxid. Med. Cell. Longev. 2009, 2, 68-72. [CrossRef]

28. Chintala, S.; Toth, K.; Cao, S.; Durrani, F.A.; Vaughan, M.M.; Jensen, R.L.; Rustum, Y.M. Se-methylselenocysteine sensitizes hypoxic tumor cells to irinotecan by targeting hypoxia-inducible factor 1alpha. Cancer Chemother. Pharmacol. 2010, 66, 899-911. [CrossRef]

29. Büntzel, J.; Micke, O.; Glatzel, M.; Schafer, U.; Riesenbeck, D.; Kisters, K.; Bruns, F.; Schänekaes, K.G.; Dawczynski, H.; Mücke, R. Selenium substitution during radiotherapy in head and neck cancer. Trace Elem. Electrolytes 2010, 27, 235-239. [CrossRef]

30. Orimo, A.; Weinberg, R.A. Stromal fibroblasts in cancer: A novel tumor-promoting cell type. Cell Cycle 2006, 5, 1597-1601. [CrossRef]

31. Arina, A.; Idel, C.; Hyjek, E.M.; Alegre, M.L.; Wang, Y.; Bindokas, V.P.; Weichselbaum, R.R.; Schreiber, H. Tumor-associated fibroblasts predominantly come from local and not circulating precursors. Proc. Natl. Acad. Sci. USA 2016, 113, 7551-7556. [CrossRef]

32. Griffith, O.W. Determination of glutathione and glutathione disulfide using glutathione reductase and 2-vinylpyridine. Anal. Biochem. 1980, 106, 207-212. [CrossRef]

33. Menon, S.G.; Sarsour, E.H.; Spitz, D.R.; Higashikubo, R.; Sturm, M.; Zhang, H.; Goswami, P.C. Redox regulation of the G1 to $S$ phase transition in the mouse embryo fibroblast cell cycle. Cancer Res. 2003, 63, 2109-2117.

34. Menon, S.G.; Sarsour, E.H.; Kalen, A.L.; Venkataraman, S.; Hitchler, M.J.; Domann, F.E.; Oberley, L.W.; Goswami, P.C. Superoxide signaling mediates $N$-acetyl-L-cysteine-induced $\mathrm{G}_{1}$ arrest: Regulatory role of cyclin D1 and manganese superoxide dismutase. Cancer Res. 2007, 67, 6392-6399. [CrossRef]

35. Huber, R.E.; Criddle, R.S. Comparison of the chemical properties of selenocysteine and selenocystine with their sulfur analogs. Arch. Biochem. Biophys. 1967, 122, 164-173. [CrossRef]

36. Chaudiere, J.; Courtin, O.; Leclaire, J. Glutathione oxidase activity of selenocystamine: A mechanistic study. Arch. Biochem. Biophys. 1992, 296, 328-336. [CrossRef]

37. Miki, K.; Xu, M.; Gupta, A.; Ba, Y.; Tan, Y.; Al-Refaie, W.; Bouvet, M.; Makuuchi, M.; Moossa, A.R.; Hoffman, R.M. Methioninase cancer gene therapy with selenomethionine as suicide prodrug substrate. Cancer Res. 2001, 61, 6805-6810.

38. Drummen, G.P.; van Liebergen, L.C.; Op den Kamp, J.A.; Post, J.A. C11-BODIPY(581/591), an oxidation-sensitive fluorescent lipid peroxidation probe: (Micro)spectroscopic characterization and validation of methodology. Free Radic. Biol. Med. 2002, 33, 473-490. [CrossRef]

39. Rotruck, J.T.; Pope, A.L.; Ganther, H.E.; Swanson, A.B.; Hafeman, D.G.; Hoekstra, W.G. Selenium: Biochemical Role as a Component of Glutathione Peroxidase. Science 1973, 179, 588-590. [CrossRef]

40. Okuno, T.; Honda, E.; Arakawa, T.; Ogino, H.; Ueno, H. Glutathione-dependent cell cycle G1 arrest and apoptosis induction in human lung cancer A549 cells caused by methylseleninic acid: Comparison with sodium selenite. Biol. Pharm. Bull. 2014, 37, 1831-1837. [CrossRef]

41. Shen, H.M.; Ding, W.X.; Ong, C.N. Intracellular glutathione is a cofactor in methylseleninic acid-induced apoptotic cell death of human hepatoma HEPG(2) cells. Free Radic. Biol. Med. 2002, 33, 552-561. [CrossRef]

42. Gordillo, G.M.; Biswas, A.; Khanna, S.; Spieldenner, J.M.; Pan, X.; Sen, C.K. Multidrug Resistance-associated Protein-1 (MRP-1)-dependent Glutathione Disulfide (GSSG) Efflux as a Critical Survival Factor for Oxidant-enriched Tumorigenic Endothelial Cells. J. Biol. Chem. 2016, 291, 10089-10103. [CrossRef]

43. McCord, J.M.; Fridovich, I. Superoxide dismutase. An enzymic function for erythrocuprein (hemocuprein). J. Biol. Chem. 1969, 244, 6049-6055.

44. Liochev, S.I.; Fridovich, I. The role of $\mathrm{O}_{2}{ }^{-}$in the production of $\mathrm{HO}:$ In vitro and in vivo. Free Radic. Biol. Med. 1994, 16, 29-33. [CrossRef]

45. Agil, A.; Fuller, C.J.; Jialal, I. Susceptibility of plasma to ferrous iron/hydrogen peroxide-mediated oxidation: Demonstration of a possible Fenton reaction. Clin. Chem. 1995, 41, 220-225.

46. Zhong, W.; Oberley, T.D. Redox-mediated effects of selenium on apoptosis and cell cycle in the LNCaP human prostate cancer cell line. Cancer Res. 2001, 61, 7071-7078. 
47. Wagner, B.A.; Buettner, G.R.; Burns, C.P. Free radical-mediated lipid peroxidation in cells: Oxidizability is a function of cell lipid bis-allylic hydrogen content. Biochemistry 1994, 33, 4449-4453. [CrossRef]

48. Accioly, M.T.; Pacheco, P.; Maya-Monteiro, C.M.; Carrossini, N.; Robbs, B.K.; Oliveira, S.S.; Kaufmann, C.; Morgado-Diaz, J.A.; Bozza, P.T.; Viola, J.P. Lipid bodies are reservoirs of cyclooxygenase-2 and sites of prostaglandin-E2 synthesis in colon cancer cells. Cancer Res. 2008, 68, 1732-1740. [CrossRef]

49. Yue, S.; Li, J.; Lee, S.Y.; Lee, H.J.; Shao, T.; Song, B.; Cheng, L.; Masterson, T.A.; Liu, X.; Ratliff, T.L.; et al. Cholesteryl ester accumulation induced by PTEN loss and PI3K/AKT activation underlies human prostate cancer aggressiveness. Cell Metab. 2014, 19, 393-406. [CrossRef]

50. Guillaumond, F.; Bidaut, G.; Ouaissi, M.; Servais, S.; Gouirand, V.; Olivares, O.; Lac, S.; Borge, L.; Roques, J.; Gayet, O.; et al. Cholesterol uptake disruption, in association with chemotherapy, is a promising combined metabolic therapy for pancreatic adenocarcinoma. Proc. Natl. Acad. Sci. USA 2015, 112, 2473-2478. [CrossRef]

51. Toth, K.; Peter, I.; Kremmer, T.; Sugar, J. Lipid-rich cell thyroid adenoma: Histopathology with comparative lipid analysis. Virchows Arch. APathol. Anat. Histopathol. 1990, 417, 273-276. [CrossRef]

52. Ericsson, J.L.E.; Seljelid, R.; Orrenius, S. Comparative light and electron microscopic observations of the cytoplasmic matrix in renal carcinomas. Virchows Archiv für Pathologische Anatomie und Physiologie und für Klinische Medizin 1966, 341, 204-223. [CrossRef]

53. Kalen, A.L.; Sarsour, E.H.; Venkataraman, S.; Goswami, P.C. Mn-superoxide dismutase overexpression enhances G2 accumulation and radioresistance in human oral squamous carcinoma cells. Antioxid. Redox Signal. 2006, 8, 1273-1281. [CrossRef]

54. Tietze, F. Enzymic method for quantitative determination of nanogram amounts of total and oxidized glutathione: Applications to mammalian blood and other tissues. Anal. Biochem. 1969, 27, 502-522. [CrossRef]

55. Wagner, B.A.; Venkataraman, S.; Buettner, G.R. The rate of oxygen utilization by cells. Free Radic. Biol. Med. 2011, 51, 700-712. [CrossRef]

(C) 2019 by the authors. Licensee MDPI, Basel, Switzerland. This article is an open access article distributed under the terms and conditions of the Creative Commons Attribution (CC BY) license (http:/ / creativecommons.org/licenses/by/4.0/). 